\title{
Modelling the flood-risk extent using LISFLOOD-FP in a complex watershed: case study of Mundeni Aru River Basin, Sri Lanka
}

\author{
G. Amarnath ${ }^{1}$, Y. M. Umer ${ }^{1,2}$, N. Alahacoon ${ }^{1}$, and Y. Inada ${ }^{1}$ \\ ${ }^{1}$ International Water Management Institute (IWMI), Colombo, Sri Lanka \\ ${ }^{2}$ Addis Ababa University, Addis Ababa, Ethiopia \\ Correspondence to: G. Amarnath (a.giriraj@cgiar.org)
}

Received: 11 March 2015 - Accepted: 11 March 2015 - Published: 11 June 2015

\begin{abstract}
Flood management is adopting a more risk-based approach, whereby flood risk is the product of the probability and consequences of flooding. Two-dimensional flood inundation modeling is a widely used tool to aid flood-risk management. The aim of this study is to develop a flood inundation model that uses historical flow data to produce flood-risk maps, which will help to identify flood protection measures in the rural areas of Sri Lanka. The LISFLOOD-FP model was developed at the basin scale using available historical data, and also through coupling with a hydrological modelling system, to map the inundation extent and depth. Results from the flood inundation model were evaluated using Synthetic Aperture Radar (SAR) images to assess product accuracy. The impacts of flooding on agriculture and livelihoods were analyzed to assess the flood risks. It was identified that most of the areas under paddy cultivation that were located near the middle and downstream part of the river basin are more susceptible to flood risks. This paper also proposes potential countermeasures for future natural disasters to prevent and mitigate possible damages.
\end{abstract}

\section{Introduction}

Flooding is one of the natural disasters that usually causes numerous problems, such as loss of life and economic losses, when it occurs in highly anthropogenic areas such as human settlements and industrial sites. According to the EMDAT report (2013), out of all the natural disasters that occur worldwide, nearly half of the deaths and one-third of all economic losses are due to flooding. Such problems vary from one place to another based on the sources of flooding and the ambient developed landscapes. The destruction caused by floods is recorded among some of the frequent events in the history of Sri Lanka. According to a disaster report from the Disaster Management Centre, Sri Lanka, there is an exponential growth in the number of flood events each year and the number of people affected at the national level. The same report indicated that the eastern part of the country (Ampara and Batticaloa districts) is categorized as a region that is intensively affected by flooding. Recent flood risks in these districts are due to temporal riverine flooding that occurs mostly after heavy rainfall, which causes the water level in the river to rise and spill out of its natural course, leading to inundation of the land that is usually dry. Therefore, holistic flood-risk management that reduces the negative impacts of flooding while increasing its positive impacts is highly needed in the region.

Flood-risk modeling is a suitable and good approach to reduce the negative socioeconomic impacts of flooding and discourage new human settlement in the flood-risk areas, as well as creating awareness amongst people living in the floodplain areas (Bates and De Roo, 2000). Different hydraulic models have been used for flood-inundation modelling, such as onedimensional (1-D) (HEC-RAS) and two-dimensional (2-D) (TELEMAC and LISFLOOD-FP) models. Recently, the 2$\mathrm{D}$ raster-based LISFLOOD-FP model has been proved as a useful numerical modelling tool for flood-inundation modelling and flood risk assessments at the river reach scale (Di Baldassarre et al., 2009). The model has been widely used in different parts of the world and is hence able to produce reliable estimates of the flood inundation extent at river reach- 


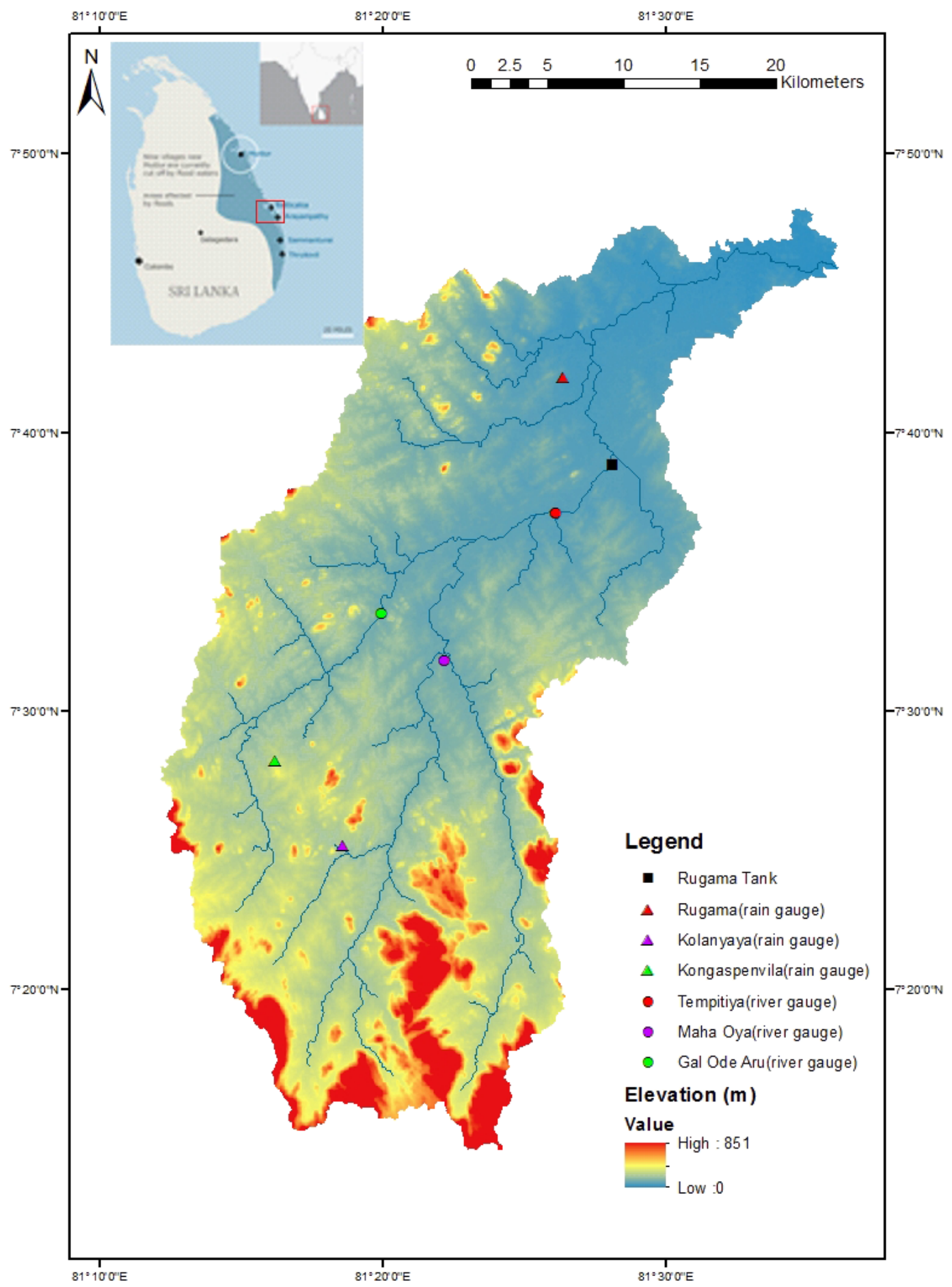

Figure 1. Location map of Mundeni Aru River Basin in the Eastern Province of Sri Lanka.

scale levels of up to $50 \mathrm{~km}$ (Horritt and Bates, 2001), as well as at large-scale levels (Wilson et al., 2007). The model used Kinematic wave equations to solve flood propagation in the main channel, and the volume filling method to produce estimates of floodplain inundation. The quality of input datasets, such as the high resolution raster file that is able to cap- ture riverbed and key topographic features, are able to determine the reliability of the model results. The performance of LISFLOOD-FP in predicting the inundation extent has been evaluated by using flood extent maps estimated from satellite (SAR) images (Pappenberger et al., 2007; Di Baldassarre et al., 2010). 


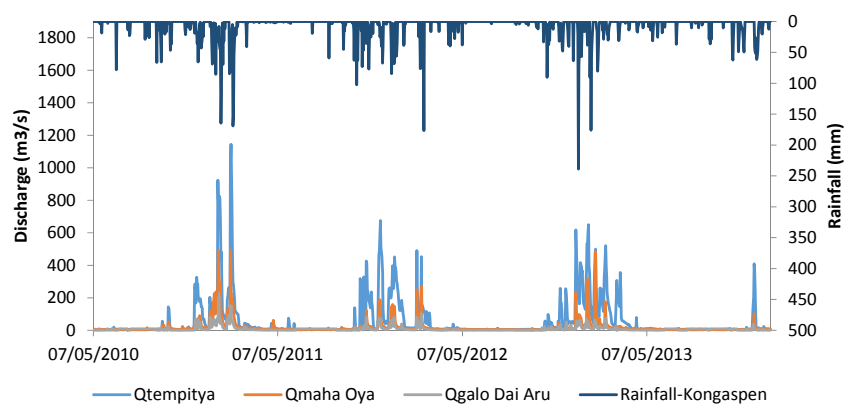

Figure 2. Historical discharge data used for flood modelling against rainfall data in the Mundeni Aru River Basin.

The current work aims to develop a flood inundation model using the LISFLOOD-FP hydraulic model, and compare its results with the flood extent maps estimated from the SAR sensor-based images. The flood inundation map developed will then be used for flood-risk assessments in the Mundeni Aru River Basin. The flood adaptation measures identified will be applied into the flood modelling system in order to evaluate its potential to reduce inundation in the basin.

\section{Materials and methods}

The study was carried out in Mundeni Aru River Basin, which is approximately $70 \mathrm{~km}$ and located between Maha Oya junction and Batticaloa Lagoon, with a slope of $0.11 \times 10^{-2}$. The study area has no sufficient discharge data for hydrological analysis. The observed discharge data is available only for 4 years starting from 2010 to date at three gauging stations: Maha Oya, Galo Dai Aru and Tempitiya stations (Figs. 1 and 2). The in-situ data was provided by the Irrigation Department of Sri Lanka and the dataset includes the flood event of 2011. The topographic data of the study area uses NEXTMap and Shuttle Radar Topography Mission (SRTM) Digital Elevation Model (DEM) with a spatial resolution of 30 and $90 \mathrm{~m}$, respectively, to investigate the role of data resolution and accuracy. The DEM is preprocessed, for example, sink-filled on Arc GIS10.1, and has a vertical accuracy of $\sim 14 \mathrm{~cm}$ root-mean-square error (RMSE). The inchannel bathymetry was not corrected according to the actual riverbed characteristics due to unavailability of ground survey cross-section data in the study area.

On 3 February 2011, a major flood event was reported with a return period of 20 years that inundated vast areas around Rugam tank and lower parts of the basin, including the adjoining lagoon areas. According to the information collected from the area, the water depth of approximately $2 \mathrm{~m}$ was marked on the house of the residents. Post-flood assessments carried out by the Ministry of Disaster Management, Sri Lanka, and the United Nations Development Programme (UNDP) indicated the occurrence of both tangible and intan- gible flood damages, such as the death of people and cattle, and damage to vast areas of agricultural land uses, with an estimated loss of LKR 2 billion.

The satellite images were obtained from Japan Aerospace Exploration Agency (JAXA) Advanced Land Observing Satellite (ALOS) Phased Array type L-band Synthetic Aperture Radar (PALSAR) with a spatial resolution of $12.5 \mathrm{~m}$ for the same period to evaluate the accuracy of model. The satellite image was processed in order to derive a flood extent map. The satellite flood extent map was produced in terms of dry/wet pixels and wet pixels, categorized into two parts as permanent water (dark red) and inundation water (light red) as shown in Fig. 3. Therefore, this flood extent map has been used for LISFLOOD-FP model verification through visual comparison.

\subsection{Hydraulic modelling}

The LISFLOOD-FP two-dimensional (2-D) hydraulic code solves a simplified version of the shallow water equations that preserve acceleration but neglect advection term. The model provides the water depth and discharge for each time step in each cell based on the raster grid being used. It was largely used for floodplain inundation and has been proved to properly perform in numerous test sites, e.g. Bates et al. (2010) and Neal et al. (2012). We, therefore, chose LISFLOOD-FP to simulate the flood extents, as it provides a good compromise between physical realism and computational efficiency.

The LISFLOOD-FP model is set up at the upstream edge of the basin where the river gauging stations are available. We used the discharge measured at Maha Oya and Gal Ode Aru stations as upstream boundary conditions, whereas the discharge measured at Tampitiya station is used as lateral flow, which considered the Rugam Tank regulation effect. To avoid assuming the shape of the hydrographs, the steady state of design flood discharges were set as the upstream boundary conditions of the LISFLOOD-FP models. The simulation periods were set as 3 days, so that possible flood inundation extents were obtained for all simulations. The downstream boundary conditions were defined using the normal depth assumption. The water surface slope is estimated as the average bed slope under the assumption of a Manning's type relationship between water stage and discharge at the downstream end of the river reach. Given that the water surface slopes are unknown, the average slope obtained from DEM for a reach of about $50 \mathrm{~m}$ from the downstream end was employed as a downstream boundary condition for all simulations.

Two different topography inputs were tested: the SRTM DEM with a resolution of $90 \mathrm{~m}$ and NEXTMap with a resolution of $30 \mathrm{~m}$. NEXTMap World 30 Digital Surface Model (DSM) is a combination of the $90 \mathrm{~m}$ SRTM v2.1 data, $30 \mathrm{~m}$ Advanced Spaceborne Thermal Emission and Reflection Radiometer (ASTER) Global DEM v2.0 and $1 \mathrm{~km}$ GTOPO which has been ground-controlled using LIDAR 


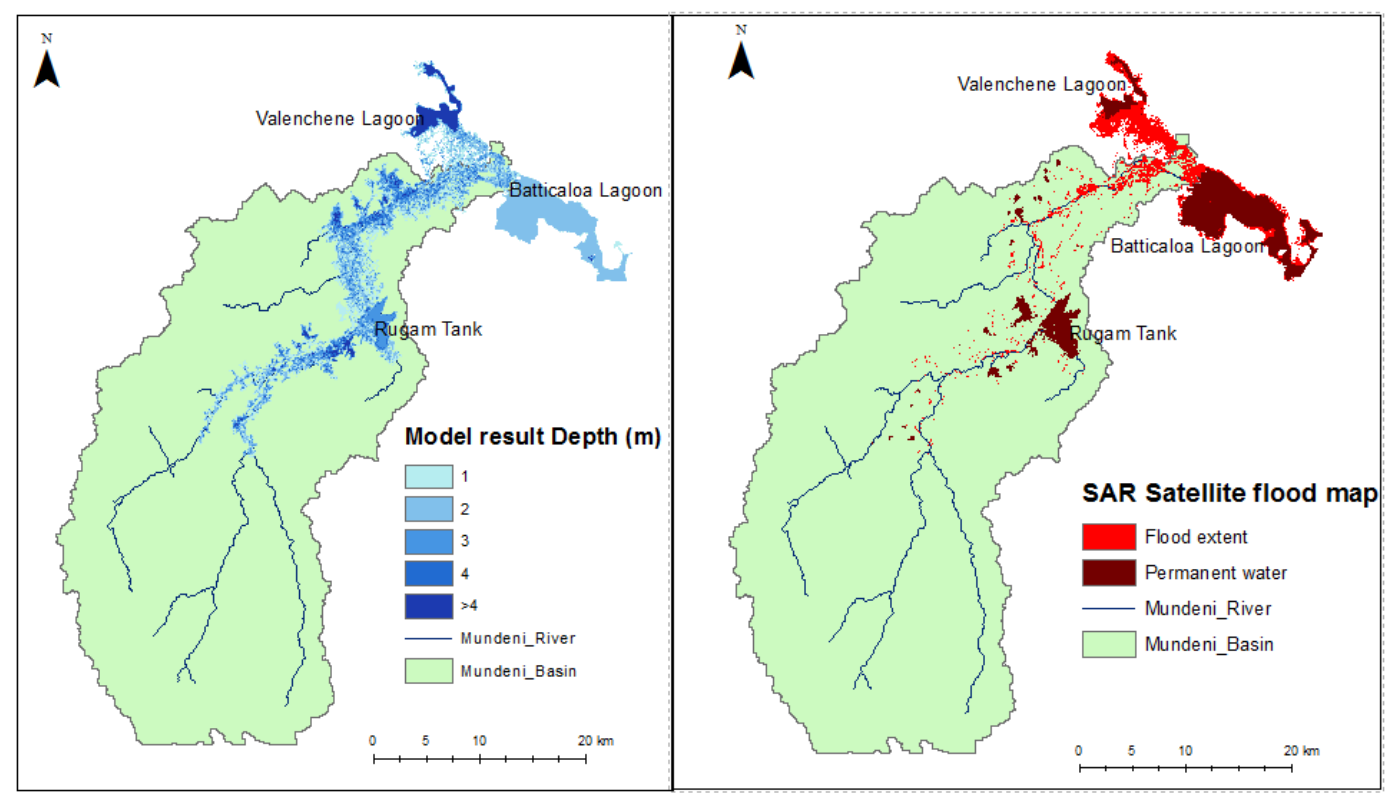

Figure 3. Flood inundation maps for the Mundeni Aru River Basin. Results from the LISFLOOD-FP model (left) and SAR satellite images (right).

data from the National Aeronautics and Space Administration's (NASA's) Ice, Cloud and Land Elevation Satellite (ICESat) collection, resulting in a $25 \mathrm{~cm}$ RMSE dataset for vertical control of the DSM. Similar to SRTM DEM, the NEXTMap $30 \mathrm{~m}$ DEM is also poorly detecting channel geometry beneath the water surface, so that the channel bed elevation is overestimated. The $30 \mathrm{~m}$ DEM has an advantage of nearly 1.5 to $2 \mathrm{~m}$ differences compared to the $90 \mathrm{~m}$ SRTM DEM. To reduce the effects of such overestimation in bed elevation, a low friction coefficient of the main channel is used in the hydrodynamic modelling (Petersen and Fohrer, 2010; Yan, 2013). Therefore, a uniform roughness parameter of 0.03 for the main channel and 0.06 for the floodplain areas are used during model simulations. The values are chosen based on standard tables of Manning 's coefficients in the scientific literature (Te Chow 1959).

\section{Results and discussion}

\subsection{Modeling inundation extent for the floods in 2011}

Taking into account the major flooding in the basin for the year 2011, the study has determined the flood extent and compared this with the satellite observation (Fig. 3). We employed a simple aggregate performance measure, $F$, which was used in many inundation modelling studies (e.g., Horritt et al. 2007) to quantitatively compare the simulated flood extent (flood of 2011) to that of SAR satellite data:

$$
F=\frac{A}{A+B+C}
$$

where: $A$ is the number of cells correctly predicted by the model, $B$ is the number of cells predicted as wet but is observed as dry (overprediction), and $C$ is the number of cells predicted as dry but is observed as wet (under-prediction). $F$ ranges from 0 to 1 . Using this equation, a low fit of 0.38 was achieved.

The results reveal a closer agreement between the two sources, in particular, near the floodplain areas of the basin. The discrepancies in the flood extent maps in other flooded areas occurred due to the different dates used for flood modelling (3 February 2011) and SAR satellite map analysis (6 February 2011). Two different dates were used because it is recommended that flood inundation modelling is conducted when the maximum flood event has occurred (e.g. 3 February 2011), whereas satellite flood map analysis can be carried out when satellite overpass is available. The result indicated that both flood inundation modelling and flood mapping using SAR satellite images captured the flood extents in the downstream part of the Mundeni Aru River Basin fairly well. Therefore, the combination of two results can be considered as a good option to better inform decision makers on floodrisk management in the data-scarce areas.

The main model parameters that control the flood inundation extents were the raster file of DEM and the values of Manning's coefficients used for the main channel and floodplain. In the case of Manning's coefficient values, the relatively optimum values chosen were 0.03 and 0.06 for the main channel and floodplain, respectively. These optimum values of $n$ were adjusted during comparison of the model results with that of the satellite flood extent map. 


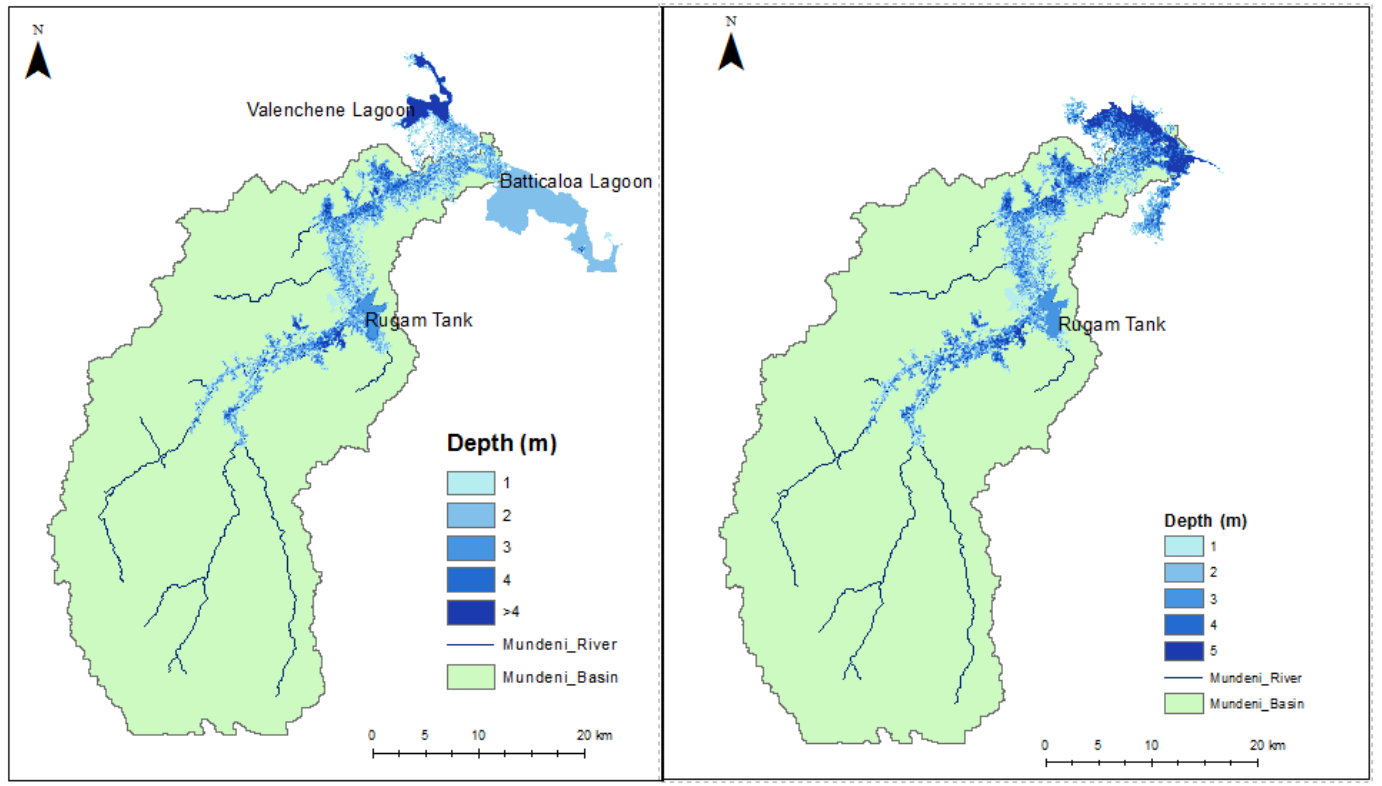

Figure 4. Flood extent maps based on 30 m DEM (left) and 90 m DEM (right) in the Mundeni Aru River Basin.

On the other hand, we tested two different raster datasets (SRTM $90 \mathrm{~m}$ DEM and NEXTMap $30 \mathrm{~m}$ DEM) to assess the resolution and accuracy of the inundation extent derived from LISFLOOD-FP (Fig. 4). By applying Eq. (1), a lower accuracy of 0.2 was achieved. The flood extent map using $90 \mathrm{~m}$ DEM is wider than that of the $30 \mathrm{~m}$ DEM when compared to result of the SAR satellite images. The reason for this is that the elevation differences between the two raster datasets are in the order of 1 to $2 \mathrm{~m}$, where the $30 \mathrm{~m}$ DEM has better vertical resolution than the SRTM DEM. In addition, the lagoon areas which were considered as having no data in the case of SRTM DEM has the favored flood extent areas by hindering flood propagation into the lagoon.

The maximum flood inundation extents were reached after 3 days (model simulation time) and the rest of floodwater directly flowed into the two lagoons (Batticaloa and Valenchine) in the downstream of the basin. Rugam Tank, which is found in the middle of the basin, is unable to hold and regulate the incoming maximum floodwater levels. Therefore, the majority of flooding near the middle of the basin is occurring as a result of water overtopping the tank height of nearly $2 \mathrm{~m}$.

Furthermore, the result of flood modelling indicates that the flood depth varies between $1 \mathrm{~m}$ around the floodplain areas to 4 meters near the vicinity of main river channel and in the ponds. The larger agricultural land in the downstream part of the basin, in particular, paddy land, has been affected by flood inundation in 2011 with the water depth varying between 1 and $2 \mathrm{~m}$. The impact of the flood inundation in 2011 on agricultural land use and other properties was further aggravated by traditional structures on the main river, such as water diversions blocking river flow to store water for irrigation purposes. The diversion of river flow created by farmers during the dry season was kept open during the flood event of 2011, and as a result floodwater followed that existing diversion to destroy farmers' paddy area. On the other hand, the river flow towards the Valenchine Lagoon was completely blocked by temporary sand bands to store water for irrigation purposes near the downstream part of basin. This blockage led to river overflows which resulted in flood inundation that affected vast areas of agricultural land in the downstream part of the basin.

\subsection{Flood countermeasures for risk assessment}

As part of the flood-risk management strategies, we proposed three multi-purpose reservoirs that have a good, unsupervised attenuation with flood storage above the spillway crest level. The reservoirs identified would be considered as multi-purpose; for instance, the floodwater stored during the flood season will be used for irrigation purposes during the dry season.

One method of flood-risk estimation in the downstream area is to take into account the presence of reservoirs. Consideration of the proposed reservoir is based on the attenuation effect (coefficient), which is estimated using Lake Area $(\mathrm{AL})$, Basin Area (AB) and spillway crest length $(L)$, the principle as stated by Miotto et al. (2007). Attenuation factor, which is also known as Synthetic Flood Attenuation (SFA) index, is the only synthetic indicator and is analogous to $(\eta)$, which varies between 0 and 1, with values less than 0.6 recommended as having a good attenuation factor for 'unsupervised' flood storage. $\eta$ can be defined in terms of flows that 


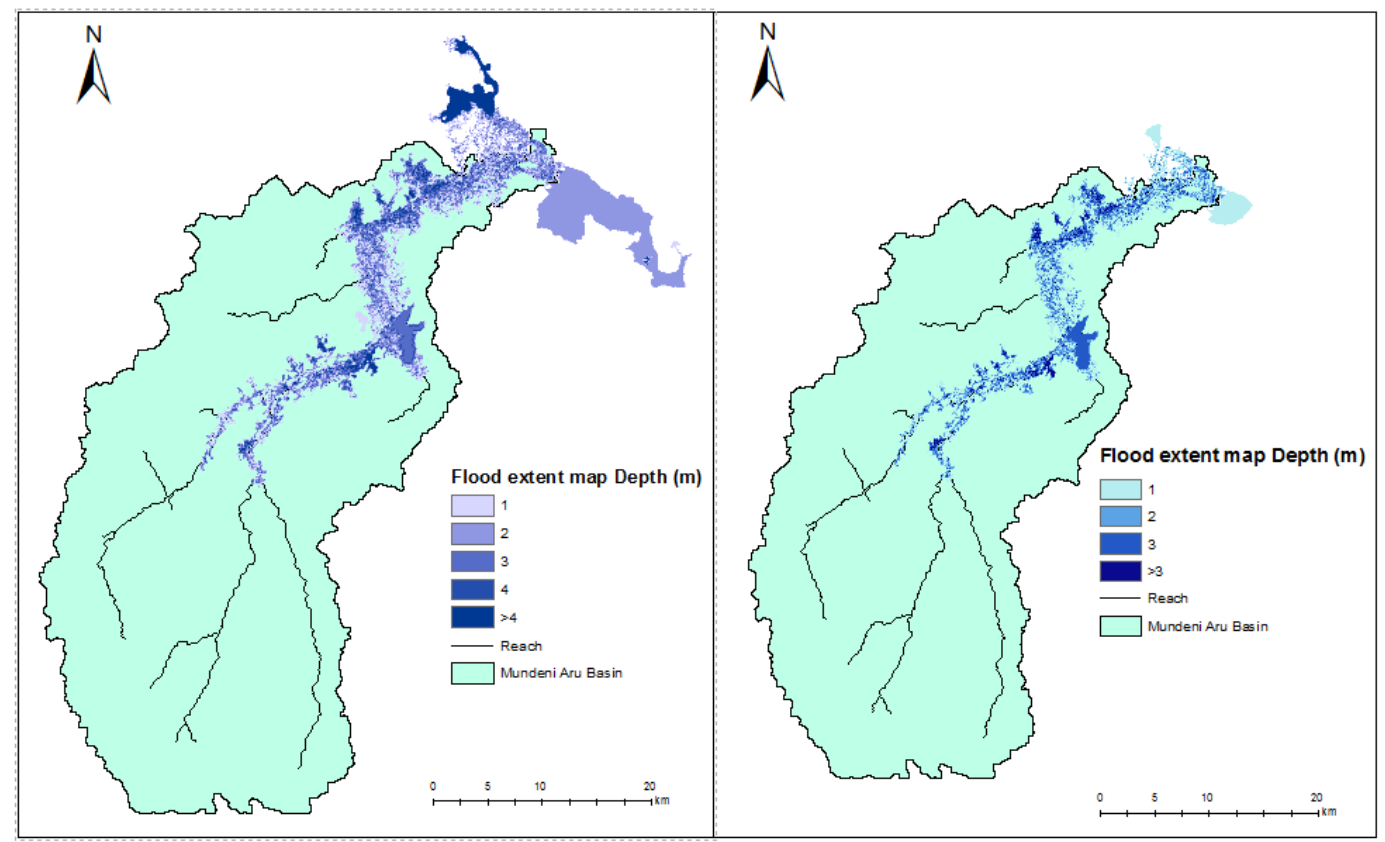

Figure 5. Flood extent map in the Mundeni Aru River Basin: without countermeasures (left) with countermeasures (right).

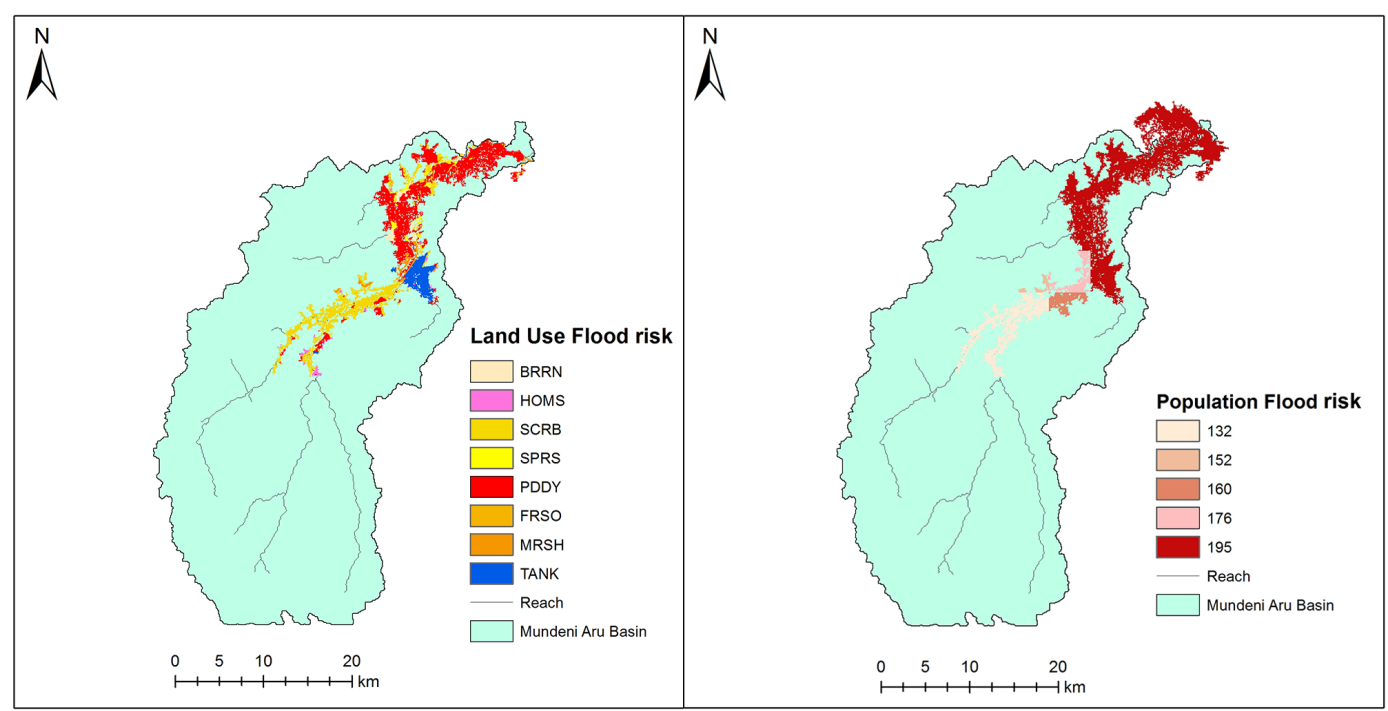

Figure 6. Flood-risk analysis: Land use (left) and population density (right) under the risk of flooding.

enter and exit the reservoir as:

$\eta=\frac{\operatorname{maxQo}}{\operatorname{maxQi}}$

where: maxQi is the maximum discharge inflow to the reservoir (maximum discharge of different return periods) and maxQo is the maximum discharge outflow from the reservoir. Knowing the maximum inflow into the reservoir, the maximum discharge outflow from the reservoir, after regu- lated by flood storage, is therefore estimated as:

$\operatorname{maxQo}=\eta \cdot \operatorname{maxQi}$

Assuming that the newly planned dams will have a good attenuation potential with good operation principles, we considered $\eta$ values of 0.6 flood-risk analysis $(\eta=0.6$ is recommended as a good attenuation factor for "unsupervised" flood storage; Miotto et al., 2007). With the construction of a dam in the upstream part of the basin, the flood risk in the downstream part (paddy area) is considerably reduced (Fig. 5). 
However, this can be the case when proper dam operations and an integrated forecasting system are introduced in the basin.

Other flood reduction measures we proposed, such as upstream forest restoration and wetland creation in the downstream part, could also play a crucial role in reducing flood risks in the basin. In general, integrating flood risk management practices that incorporate both structural (proposed dams) and non-structural measures could be crucial to reducing flood risk and to also increase other socioeconomic aspects, such as irrigation purposes in the basin, at the same time.

Flood risk is assessed in terms of land-use types affected by flooding and population density. The study area is typically rural catchment that is characterized by different landuse types, the majority of which is agricultural land use, in particular, under paddy cultivation. The lowland areas of the basin (delta area) are one of the fertile areas, partially due to humus soil as a result of flooding during the wet season. However, major flood events such as that of 2011 still negatively affect those areas through inundation extents that swallow agricultural lands. During the flood events of 2011, nearly $90 \%$ of the paddy area was inundated. In particular, the areas downstream of Rugam Tank are those that were affected by flood events (Fig. 6). Based on the stages of crop yield, the level of damage could be different.

A population flood risk map can be produced using demographic data available in the basin. In this case study, we used a satellite-based estimation and reclassified it according to the population density per square kilometer in the basin. The flood risk map is, therefore, produced by overlaying population density data with that of the flood inundation map. Areas with a relatively high population density, such as those near Rugam Tank and delta areas, are under threat of floods. Results of the analysis indicated that those populations living in the downstream areas and near the vicinity of the river stream are at risk of flooding.

\section{Conclusions}

The results show that the LISFLOOD-FP hydraulic model provides more than a $80 \%$ fit to the extent of a real flood event using SAR images. Majority of the agricultural land and population in the mid-elevation and downstream areas of the basin is highly susceptible to floods. However, with the application of the proposed flood countermeasures, such as constructing new dams and creating new wetlands, the flood inundation extents could be reduced by more than a half when operated properly.

In general, a gap still exists in flood-risk modelling in the data-scarce areas, where data limitation and quality creates a shadow for flood-risk mitigation, especially in the rural areas with high vulnerability to floods. In those areas, a flood inundation model, based on freely available global data, might not be sufficient for flood-risk mitigation. However, the combination of both satellite data and a flood inundation modelling system can still better inform decision makers for flood-risk management activities, such land-use planning.

The Mundeni Aru River Basin is a poorly developed region in Sri Lanka. Being the food-basket for the surrounding communities, it has been affected by recursive flooding and droughts interchangeably. This case study has identified the mechanisms to reduce flood risks while increasing productivity through the construction of multi-purpose reservoirs in the basin. We proposed three multi-purpose reservoirs that could potentially reduce flood risks in the basin and also be used for irrigation purposes, which seemed to halt the drought problems. The efficiency of the reservoirs identified would rely on its appropriate operational aspects, in such a way that some parts of the reservoirs should be left empty to store sufficient water from the forthcoming flood event. The stored floodwater will be used at a later time for irrigation and water supply purposes. In addition, non-structural flood measures, such as forest restoration, recreating wetlands in the downstream part of the basin, flood insurance and a basin-wide forecasting system, could be other options to reduce flood risks. In general, integrating flood-risk management practices that include both structural and non-structural measures would be best for the Mundeni Aru River Basin.

Acknowledgements. This research was funded by the Ministry of Agriculture, Forestry and Fisheries (MAFF), Japan; the CGIAR Research Program on Water, Land and Ecosystems (WLE); and the International Water Management Institute (IWMI). We would like to thank Vladimir Smakhtin (Theme Leader - Water Availability, Risk and Resilience, IWMI) and Herath Manthrithilake (Head, Sri Lanka Development Initiative, IWMI) for their inspiring guidance and encouragement, and also the Department of Irrigation, Survey Department of Sri Lanka, and Department of Meteorology for sharing their data.

\section{References}

Bates, P. and De Roo, A.: A simple raster-based model for flood inundation simulation, J. Hydrol., 236, 54-77, 2000.

Bates, P., Horitt, M. S., and Fewtrell, T. J.: A simple inertial formulation of the shallow water equations for efficient twodimensional flood inundation modelling, J. Hydrol., 387, 33-45, 2010.

Di Baldassarre, G., Schumann, G., and Bates, P. D.: A technique for the calibration of hydraulic models using uncertain satellite observations of flood extent, J. Hydrol., 367, 276-282, 2009.

Di Baldassarre, G., Schumann G., and Bates, P. D.: A technique for the calibration of hydraulic models using uncertain satellite observations of flood extent, J. Hydrol., 367, 276-282, 2009.

EM-DAT: The OFDA/CRED International Disaster Database. http: //www.emdat.net - Université catholique de Louvain - Brussels - Belgium, last access: 27 August 2013. 
Horritt, M. S. and Bates, P. D.: Predicting floodplain inundation: raster-based modelling versus the finite-element approach, Hydrol. Process., 15, 825-842, 2001.

Miotto, F., Claps, P., Laio, F., and Poggi D.: An analytical index for flood attenuation due to reservoirs. 32nd Congress of IAHR, edited, Venice, Italy, 2007.

Neal, J., Schumann, G., and Bates, P. D.: A subgrid channel model for simulating river hydraulics and floodplain inundation over large and data sparse areas, Water Resour. Res., 48, W11506, doi:10.1029/2012WR012514, 2012.

Pappenberger, F., Frodsham, K., Beven, K., Romanowicz, R., and Matgen, P.: Fuzzy set approach to calibrating distributed flood inundation models using remote sensing observations, Hydrol. Earth Syst. Sci., 11, 739-752, doi:10.5194/hess-11-739-2007, 2007.
Petersen, G. and Fohrer, N.: Two-dimensional numerical assessment of the hydrodynamics of the Nile swamps in southern Sudan, Hydrol. Sci. J., 55, 17-26, 2010.

Te Chow, V.: Open channel hydraulics, 131, p. 1215, 1959.

Wilson, M., P. Bates, P., Alsdorf, D., Forsberg, B., Horritt, M., Melack, J., Frappart, F., and Famiglietti, J.: Modeling large-scale inundation of Amazonian seasonally flooded wetlands, Geophys. Res. Lett., 34, L15404 doi:10.1029/2007GL030156, 2007.

Yan, K., Di Baldassarre, G., and Solomatine, D. P.: Exploring the potential of SRTM topographic data for flood inundation modelling under uncertainty. Journal of Hydroinformatics, 15, 3, 849-861, 2013. 